\title{
Study of Diet Recommendation System based on Fuzzy Logic and Ontology
}

\author{
Shital V. Chavan \\ Department of Computer Engineering \\ Pimpri Chinchwad College of Engineering \\ Pune-44
}

\author{
S.S. Sambare \\ Department of Computer Engineering \\ Pimpri Chinchwad College of Engineering \\ Pune-44
}

\begin{abstract}
People are becoming very conscious about their health. Universe is changing at every moment and results in seasonal variations. These seasonal variations affect on human body. Every individual having their own unique prakriti from their birth. Prakriti is one type of energy to maintain physical and mental state of human body. Imbalance in these energies results in illnesses and different diseases. For maintaining health and prevent diseases, diet is the best medicine in Ayurveda. People follow different diet plans recommended from different dietician. This recommendation is manual recommendation, in computer aided world this is taken as slow process. For recommending diet instead of manually, different approaches from computer science are used. In this paper different existing diet recommendation approaches studies based on fuzzy approaches and ontology and knowledge representation methods, and proposed a method to recommend diet based on prakriti of person and current season.
\end{abstract}

\section{Keywords}

Prakriti, Season, Fuzzy logic, Ontology, Diet recommendation.

\section{INTRODUCTION}

"Diet" is one of the three supporting factors of life, plays a key role in maintaining health and prevention of diseases. In Modern Science the balanced diet is one which contains a variety of foods in such quantities and proportions that the need for energy, proteins, vitamins, minerals, fats, carbohydrates and other nutrients is adequately met for maintaining health. According to Ayurveda the diet which nourishes both the mental and physical built is called "balanced diet"[1].

Health of human being is totally depend on diet. Human body is made from "tridoshas" and is called as "prakriti". In Ayurveda "Prakriti (Dosha)" is called as root of body. "Prakriti" plays important role in healthy or sick body. When all these "Dosha" are in their normal proportions then person remains healthy but the moment their proportion is disturbed person falls sick. In the human body these "Dosha" are present with certain proportion. Disorder in human health because of disturbance of the combination of these "Dosha"[2]. Seasonal variations affect on human body. As physical activities is changes seasonality. Proper diet helps to maintain health. There are various different techniques used to recommending diet for people having different diseases also for normal users. Fuzzy technique giving good results in real word problem to recommend personalized diet with different uncertainty and ontology is used to represent this knowledge.

Dietician having experience and skill for interpreting and analyzing health related issues by seeing person. The intelligence and knowledge of the dietician is approximate and not exact in nature. The medical parameters are not precise in nature. They may be precise to a certain degree. The degree of precision is important and therefore the fuzzy logic concept is used to represent the fuzziness of the parameters. Ontology is used to represent knowledge in tree like manner with concept and related instances. The use of fuzzy logic with ontology offers a solution to handle uncertainties and vagueness in information. In diet recommendations most of the time dieticians tell patients to take food in quantities like use spices in small amount, fruits in large amount, oil in moderate amount. So this small, moderate ,normal, low ,high and medium are not in number format so represent those words in computer language is not easy task and also for use.

This paper provides a review on different techniques used for recommending diet for people using fuzzy logic and ontology. First terminologies related to Ayurveda are discussed in section 2, in section 3 fuzzy related concepts are discussed, in section 4 Fuzzy ontology related concepts are discussed, in section 5 Related work is discussed, in section 6 proposed work is discussed and in section 7 at last conclusion

\section{AYURVEDA RELARED CONCEPTS}

\subsection{Prakriti}

In Ayurveda, each and every individual is unique. Their size and shape are different, even their physiological and psychological characters and behavior are also different. This is because they have different proportion of dosha (vata, Pitta and Kapha) at the time of birth which decides their constitution. Once this constitution is set, it is permanent for that individual [3]. Type of different Prakriti is shown in figure 1.

\subsection{Season}

According to Ayurveda year is divided into "six seasons". Each season consist of two months and in every season particular prakriti raises their proportion in human body and which results in illnesses. For example in winter season vata prakriti people facing problems related to health like pain in Joints. Figure 2 shows relationship between prakriti and season.

\subsection{DIET}

"Diet" is the best medicine in Ayurveda to keep maintains health and diet is given in planned way, there is no need for separate medical treatment [1]. For different prakriti and depend on season every individual have to take unique diet. Same diet is not used for number of people. 


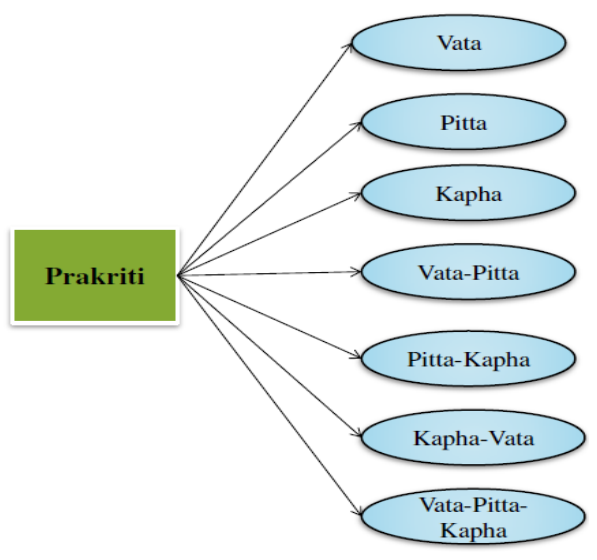

Figure 1. Types of Prakriti

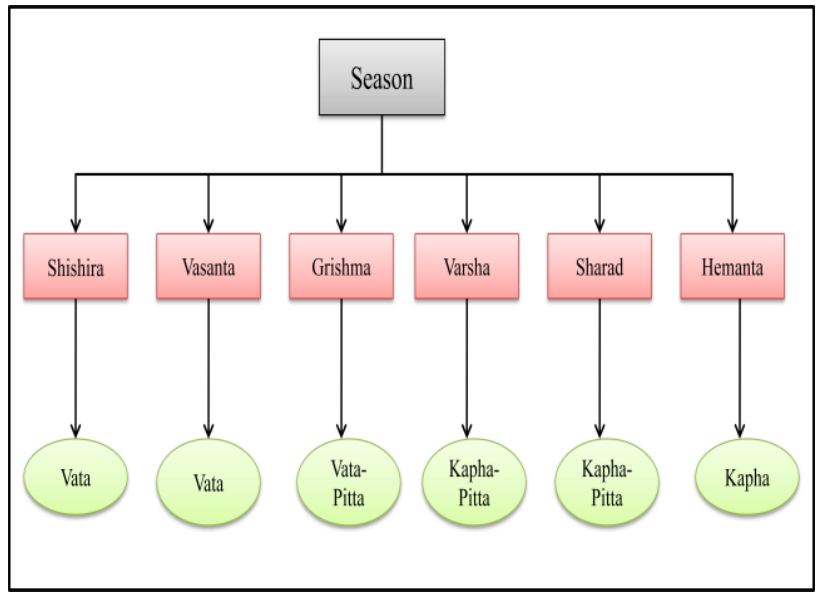

Figure 2. Relationship between Season and Prakriti

\section{FUZZY RELATED CONCEPTS}

\subsection{Fuzzy Logic}

Fuzzy logic is represented using fuzzy sets, sets that express uncertainty, fuzzy logic is based on the concept of membership degrees and fuzzy logic is designed to mathematically represent uncertainty for dealing with the inbuilt vagueness in some domains. Normally logic is comprised of only two values i.e. true and false and has its constraints in dealing with problems related to the real world domain. Fuzzy logic uses logical values between 0 and 1[4].

\subsection{Fuzzy Set}

In the fuzzy theory, fuzzy set $\mathrm{F}$ of universe $\mathrm{U}$ is defined by a membership function. It is denoted by $\mu \mathrm{F}(\mathrm{x})$ such that $\mu \mathrm{F}(\mathrm{x})$ : $\mathrm{F} \rightarrow[0,1], 1$ if $\mathrm{x}$ is totally in $\mathrm{F}, \mu \mathrm{F}(\mathrm{x})=0$ if $\mathrm{x}$ is not in $\mathrm{F}$. For any element $x$ of universe $X$, membership function $\mu \mathrm{F}(\mathrm{x})$ equals the degree to which $\mathrm{x}$ is an element of set $\mathrm{F}$. Degree having a value between 0 and 1 which represents the degree of membership and also called as membership value of element $\mathrm{x}$ in set $\mathrm{F}$ [4].

\subsection{Type-1 and Type-2 Fuzzy Logic}

The type-1 FLSs can operate well under specific operation conditions. The linguistic and numerical uncertainties can make problems in determining the exact and precise antecedents and consequent membership functions during the FLS design. As time goes every user behavior and preferences change from one person to another; also, the domain experts opinions are also vary. Hence, the effectiveness of the type-1based system will goes down when there are high uncertainty levels that are related with the diet domain [5].

Type-2 FLSs used to handle the uncertainties in the groupdecision-making process as they can model the uncertainties between expert opinions using type-2 fuzzy sets. A T2FS is characterized by a fuzzy Membership function, the membership value for each element of this set is a fuzzy set in 0,1 and in between 0 and 1 , in T1FS, where the membership function value is a crisp number in exactly 0 or 1 . The MFs of T2FSs are three-dimensional and include a footprint of uncertainty (FOU). To model the group uncertainties T2FSs provide additional degrees of freedom that can make it possible, which involve the different opinions and preferences of experts [5]. The T2FSs can model the requirements of a person specification that is reflective of all the experts' opinions and which can then be used to provide a good recommendation for the diet [5].

\section{FUZZY ONTOLOGY}

Ontology is a method used for representing a piece of knowledge and its relationship to other pieces of knowledge [6]. Because ontology is not sufficient to deal with uncertainty or vagueness, they are extended with fuzzy data to compose fuzzy ontology, a fuzzy ontology provide a degree of truth to an ontology, which describes the degree to which an item is an instance of a class of items, this is useful for constructing a set of knowledge for a domain [6].

Fuzzy ontology is representing hierarchical relationship between concepts in a particular domain and which can be viewed as a graph. As many fuzzy Concepts are rather vague than precise and the fuzzy ontology is capable of dealing with fuzzy knowledge [7].

Fuzzy ontology is defined as the tuple $\langle\mathrm{I}, \mathrm{C}, \mathrm{R}, \mathrm{F}, \mathrm{A}>[8]$. I is the set of individuals, also called instances of the concepts. C is the set of concepts. Each concept $\mathrm{C} \in \mathrm{C}$ specifies a fuzzy set on the domain of instances, that is, $\mathrm{C}: \mathrm{I} \rightarrow[0,1]$. The set of entities of the fuzzy ontology will be indicated by $\mathrm{E}$ where $\mathrm{E}=\mathrm{C} \cup \mathrm{I}$. R is the set of relations. Each $\mathrm{R} \in \mathrm{R}$ is a $\mathrm{n}$-ary fuzzy relation on the domain of entities so that $\mathrm{R}: \mathrm{En} \rightarrow[0$, 1]. This part of the fuzzy definition appears to apply to relations between concepts, and relations between concepts and instances. A special role is held by the taxonomic relationship T: $\mathrm{E} 2 \rightarrow[0,1]$ among the entities. The $\mathrm{C}: \mathrm{I} \rightarrow[0$, 1] function seems to define the is-a between an instance and a concept $\mathrm{C}$. F is the set of the fuzzy relations on the set of entities. A is the set of axioms defined using a suitable logical language [8].

\section{RELATED WORK}

Chang-Shing Lee, Mei-Hui Wang, and Shun-Teng Lan et al [9]. Proposed an Adaptive Personalized Diet Linguistic Recommendation Mechanism based on Type-2 Fuzzy Logic System (T2FLS) and Genetic Fuzzy Markup language (GFML). First, by using domain expert an adaptive dietary assessment and recommendation ontology is constructed and then a T2FS-based GFML is constructed, the fuzzy knowledge base and the fuzzy rule base of the proposed mechanism is describing by using genetic algorithms. The input type of information is about the eaten meal and proposed mechanism is used to improve their unhealthy eating habit and then become healthier and healthier.

Chang-Shing Lee, Chin-Yuan Hsu, Su-E Kuo, Akio Naito at al [10]. This paper presented diet recommendation system 
based on genetic fuzzy markup language to describe the knowledge base and rule base of the diet domain, including six food categories of some common food. To construct the fuzzy food ontology the domain experts first define the nutrient facts of the common food. GFML-based learning mechanism combining the genetic learning mechanism with the fuzzy markup language and is carried out to infer the possibility of dietary healthy level for one-day meals.

Wahidah Husain, Lee Jing Wei, Sooi Li Cheng and Nasriah Zakaria et al [11]. Proposed a Personalized Diet Recommendation System for Cancer Patients to help patients for manage their daily food intake. The proposed system combines Case-based Reasoning, Rule-based Reasoning and Genetic Algorithm to recommend suitable diet as per patients information. Using Case-based Reasoning set of diet plans taken from the cases which are already present in the system are suggested, whereas Rule-based Reasoning is used to filter out cases which are irrelevant from the system and select the approximately matching case to be suggested to the patient. The Genetic Algorithm technique ensures that the diet menus suggested are customized according to each patient's personal health conditions.
Mei-Hui Wang, and Hani Hagras et al [5]. This paper proposes a new ontology model, which is based on interval type-2 fuzzy sets, called type-2 fuzzy ontology, for knowledge representation in the field of personal diabetic-diet recommend. First, plan the diet goals are taken from domain experts for the involved diabetes and create the nutrition facts of common Taiwanese food. Second, daily input eaten items of diabetic patient are taken. Third, the ontology-creating mechanism constructs a T2FO, including a type- 2 FPPO, a type-2 FFO, and a set of type- 2 FPFOs. Finally, the T2FSbased system retrieves the built T2FO to recommend a personal diabetic meal plan.

Chang-Shing Lee, Mei-Hui Wang, Zhi-Wei Chen, Chi-Fang Lo, Su-E Kuo, Hui-Ching Kuo and Hui-Hua Cheng et al [12]. In this paper property of fuzzy ontology is proposed for diabetes and cardiovascular diseases. Using type-2 fuzzy sets and fuzzy inference approach and giving dietary healthy level from users eating habits. Following table 1 shows study of five papers related to diet recommendation systems

Table 1. Survey Table

\begin{tabular}{|c|c|c|c|c|}
\hline $\begin{array}{l}\text { Sr. } \\
\text { No }\end{array}$ & Paper Title & Techniques & Input & Output \\
\hline 1 & $\begin{array}{l}\text { Adaptive Personalized } \\
\text { Diet } \quad \text { Linguistic } \\
\text { Recommendation } \\
\text { Mechanism Based on } \\
\text { Type-2 Fuzzy Sets and } \\
\text { Genetic Fuzzy Markup } \\
\text { Language.( 2015) }\end{array}$ & $\begin{array}{l}\text { 1.Type-2 FS } \\
\text { 2.Genetic } \\
\text { fuzzy } \\
\text { markup } \\
\text { language }\end{array}$ & $\begin{array}{l}\text { Eating } \\
\text { Habit }\end{array}$ & $\begin{array}{l}\text { Healthy } \\
\text { diet }\end{array}$ \\
\hline 2 & $\begin{array}{l}\text { Genetic Fuzzy Markup } \\
\text { Language for Diet } \\
\text { Application.(2011) }\end{array}$ & $\begin{array}{l}\text { 1.Fuzzy } \\
\text { markup } \\
\text { language } \\
\text { 2.Genetic } \\
\text { algorithm }\end{array}$ & $\begin{array}{l}\text { Eaten } \\
\text { food }\end{array}$ & $\begin{array}{l}\text { Health } \\
\text { level }\end{array}$ \\
\hline 3 & $\begin{array}{l}\text { Application of Data } \\
\text { Mining Techniques in a } \\
\text { Personalized r Diet } \\
\text { Recommendation System } \\
\text { for Cancer Patients. } \\
(2011)\end{array}$ & 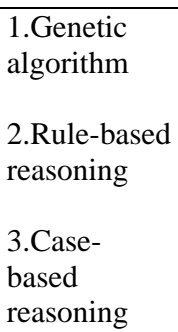 & $\begin{array}{l}\text { Cancer } \\
\text { patient } \\
\text { Inform- } \\
\text { ation }\end{array}$ & $\begin{array}{l}\text { Diet } \\
\text { Plan }\end{array}$ \\
\hline 4 & $\begin{array}{l}\text { A Type-2 Fuzzy } \\
\text { Ontology and its } \\
\text { Application to Personal } \\
\text { Diabetic-Diet } \\
\text { Recommendation. (2010) }\end{array}$ & $\begin{array}{l}\text { 1.Type-2 } \\
\text { fuzzy set } \\
\text { 2.Type-2 } \\
\text { fuzzy }\end{array}$ & $\begin{array}{l}\text { Diet } \\
\text { goal } \\
\text { and } \\
\text { user } \\
\text { profile }\end{array}$ & $\begin{array}{l}\text { Diet } \\
\text { Plan }\end{array}$ \\
\hline
\end{tabular}




\begin{tabular}{|l|l|l|l|l|}
\hline & & ontology & & \\
\hline 5 & $\begin{array}{l}\text { Property and Application } \\
\text { of Fuzzy Ontology for } \\
\text { Dietary Assessment. } \\
(2010)\end{array}$ & $\begin{array}{l}\text { Type-2 } \\
\text { fuzzy } \\
\text { Ontology }\end{array}$ & $\begin{array}{l}\text { Eaten } \\
\text { food } \\
\text { and } \\
\text { BMI }\end{array}$ & $\begin{array}{l}\text { Health } \\
\text { level }\end{array}$ \\
& & & \\
\hline
\end{tabular}

\section{PROPOSED WORK}

In proposed system as shown in figure 3, type-2 fuzzy logic and fuzzy ontology is integrated to recommend diet for user. Type-2 fuzzy logic is used to deal with uncertain things which are come from group of different dieticians. Fuzzy ontology is used to generate food ontology with help of fuzzy concept, fuzzy variable and fuzzy sets. This fuzzy ontology helps to represent uncertain things in efficient manner and knowledge is extracted based

on membership value of variables. Database is created by collecting data related to diet for different prakriti and season wise diet from different websites, Ayurvedic books and dieticians.

Working of proposed system is as follow:

1. User enter their health information.(age, sex, weight, height) .

2. User enters prakriti type.

3. User enter current season.
4. On collected database fuzzy ontology is apply

5. Using input values Type-2 fuzzy profile is created.

6. For personal diet recommendation fuzzy food ontology and Type-2 fuzzy profile ontology is created.

7. Diet menu is recommended to user.

\section{CONCLUSION}

In this paper different diet recommendation system are studied based on fuzzy logic approaches and ontology. The use of fuzzy logic with ontology will offers a solution to handle uncertainties and vagueness in information. From study we proposed a method for diet recommendation using type-2 fuzzy logic and fuzzy ontology techniques. Type-1 fuzzy logic having disadvantage of when dealing with more number of uncertain things increases and not giving proper results.Type-2 fuzzy logic is used to handle uncertain things coming from different opinions and overcome disadvantage of Type-1 fuzzy logic. Ontology is integrated with fuzzy concepts to represent uncertain things.

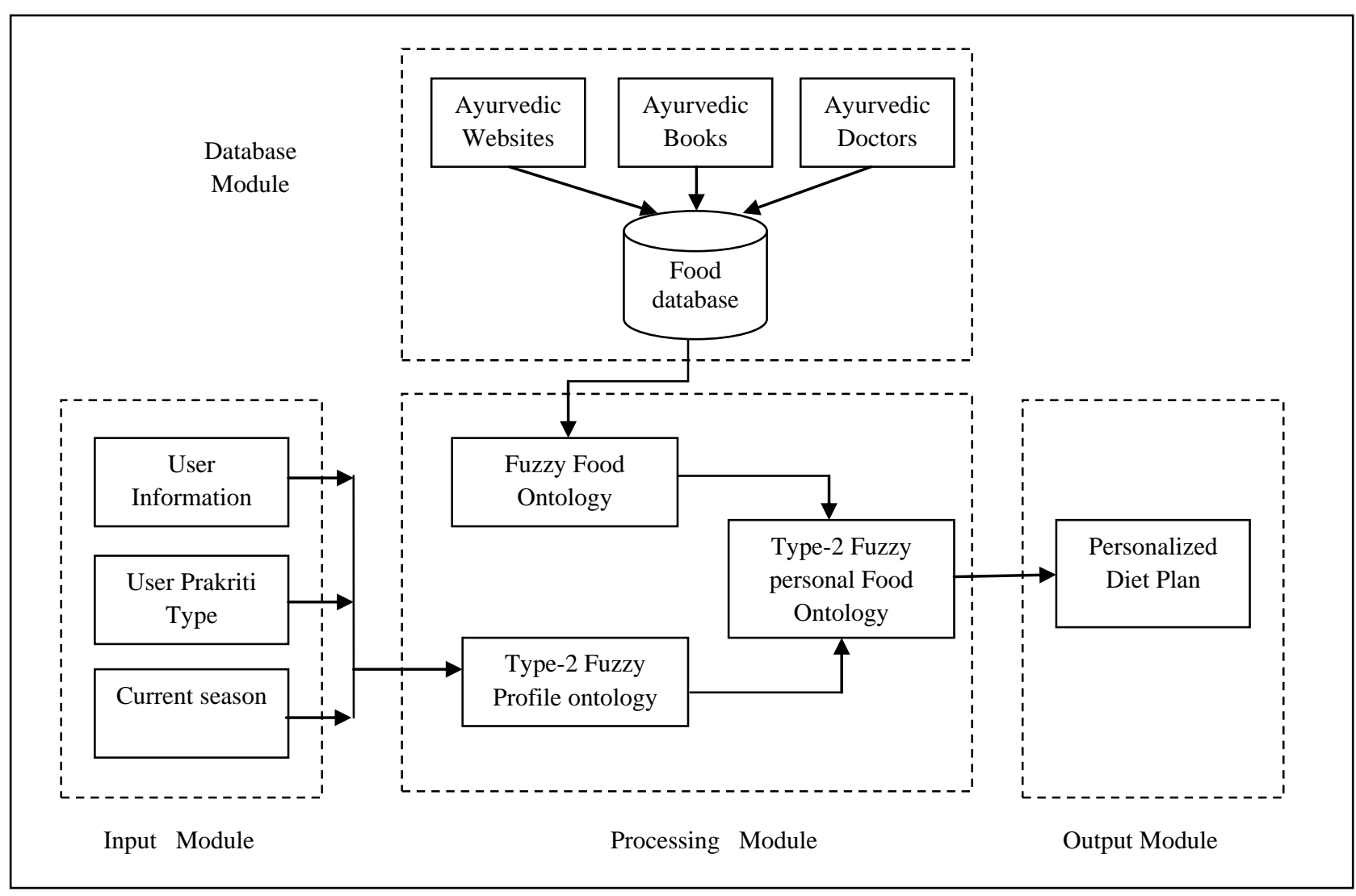

Figure 3. Architecture of Proposed Work 


\section{REFERENCES}

[1] Dr. Neeru Nathani. 2013. An appraisal of the concept of Diet and Dietetics Ayurveda. Asian Journal of Modern and Ayurvedic Medical Science (ISSN 2279-0772) Vol.2, no.1.

[2] S. Kher, An jana Jain, M.K. Ojha, G.N. Sharma. 1996. Intelligent Diagnosis of Human Disorders based on Ayurveda.

[3] Chaudhary Sunil Kumar and Tripathi N. S. 2013. Study Of Seasonal Variations In Different Prakriti Persons With Special Reference To Serum Urea. International Journal Of General Medicine And Pharmacy (Ijgmp) Issn 2319-3999 Vol. 2, Issue 3, 23-28.

[4] Tanumeet Kaur, Amardeep Kaur. 2012. Extension of A Crisp Ontology to Fuzzy Ontology. International Journal Of Computational Engineering Research (ijceronline.com) Vol. 2.

[5] Mei-Hui Wang, and Hani Hagras. 2010. A Type-2 Fuzzy Ontology and Its Application to Personal Diabetic-Diet Recommendation. IEEE Transactions On Fuzzy Systems, Vol. 18, No. 2.

[6] Joshua M. Krbez, Adnan Shaout. 2013. Fuzzy Nutrition System. International Journal of Innovative Research in Computer and Communication Engineering (An ISO 3297: 2007 Certified Organization) Vol. 1.
[7] Nilavu Devadoss, Sivakumar Ramakrishnan. 2015 Knowledge Representation using Fuzzy Ontologies - A Review. International Journal of Computer Science and Information Technologies, Vol. 6 (5).

[8] V.V. Cross. 2014. "Fuzzy Ontologies: The State of the Art. IEEE.

[9] Chang-Shing Lee, Mei-Hui Wang, and Shun-Teng Lan. 2015. Adaptive Personalized Diet Linguistic Recommendation Mechanism Based on Type-2 Fuzzy Sets and Genetic Fuzzy Markup Language. IEEE Transactions on Fuzzy Systems, Vol. 23, No. 5.

[10] Chang-Shing Lee, Mei-Hui Wang,Zhi-Wei Chen. 2011. Genetic Fuzzy Markup Language for Diet Application. 2011 IEEE International Conference on Fuzzy Systems June 27-30.

[11] Wahidah Husain, Lee Jing Wei, Sooi Li Cheng and Nasriah Zakaria. 2011. Application of Data Mining Techniques in a Personalized Diet Recommendation System for Cancer Patients. 2011 IEEE Colloquium on Humanities, Science and Engineering Research (CHUSER 2011), Dec 5-6.

[12] Chang-Shing Lee, Mei-Hui Wang, Zhi-Wei Chen, ChiFang Lo, Su-E Kuo, Hui-Ching Kuo and Hui-Hua Cheng. 2009. A Novel Type-2 Fuzzy Ontology and Its Application to Diet Assessment. IEEE/WIC/ACM International Joint Conferences on, vol.3, 15-18. 